\title{
On Compensation for Occupational Injuries and Diseases
}

\section{Mncedisi Michael Willie*}

\author{
Multinum, Postnet Suite 427, Private Bag X37, Lynwood ridge, South Africa
}

${ }^{*}$ Corresponding author: Mncedisi Michael Willie, Multinum, Postnet Suite 427, Private Bag X37, Lynwood ridge, South Africa, Tel: +2776122 2369; E-mail: mwillie@multinum.co.za

Received date: March 20, 2018; Accepted date: March 23, 2018; Published date: March 28, 2018

Citation: Willie MM (2018) On Compensation for Occupational Injuries and Diseases. Med Clin Rev. Vol. 4 No. 1: 4.

Copyright: (c) 2018 Willie MM. This is an open-access article distributed under the terms of the Creative Commons Attribution License, which permits unrestricted use, distribution, and reproduction in any medium, provided the original author and source are credited.

Keywords: Disease; Compensation benefits; Pension benefits; Insurance; liabilities

\section{Contextualization}

Injury or disease in the workplace is a risk that is unlikely to avoid, this is mainly as a result of varying risks associated with the nature of work. Employees are generally not aware of their rights to claim compensation benefits, similarly employers, do not fully understand their role in an employer/employee relation in respect of an injury/disease on duty. This lack of understanding ultimately impact on compensation benefits thereof.

A study by Hsiao-YuYang [1] revealed that awareness of labour insurance benefits was poor among workers. The study assessed the level of awareness of compensation claims for occupational injuries and diseases among workers and the general public, small and large enterprises. The results of the study found that lack of awareness of compensation benefits for occupational injuries were mainly lower in small enterprises, and the general public.

It is a known phenomenon that when insured lives are not aware of their benefits they tend not to claim for such benefits. There's a great body of literature that illustrates that work-related injuries and diseases are under-reported and that a reliance on workers' compensation data undermines the recognition of the full public health burden of these injuries and fatalities. Under-reporting of fatalities may be due to a lack of awareness by family members of death or pension benefits for a deceased worker, or a lack of reinforcements for reporting fatalities to the workers' compensation system (i.e., no perceived benefits and the death has been recorded by other agencies). Many reasons for under reporting work related fatalities may be due to a lack of awareness by family members of death or pension benefits for a deceased worker [2].

In other instances work-related injuries not captured due system inefficiencies, or the process is just too cumbersome for the claimants as a result agencies that are tasked to administer workmen's compensation do not collect all the data. Studies have shown that some work-related injuries are captured by external data sources than workers' compensation [2]. A study by Chen [3] indicates lack of familiarity with regulations as one obstacles to claiming compensation from labour insurance include injured workers' lack of familiarity with regulations, in some instances the process is burdensome as a result employees end up not claiming.

\section{Socio Economic Effect}

Injury in the workplace, in particular severe injuries that impact the quality of life of injured employees has long term effect. International studies such as that conducted by OSHA [4] state that workplace injury creates a trap which leaves most injured employees and their families less able to save for the future or to make the investments in skills and education that provide the opportunity for advancement. This further creates to high levels of unemployment and poverty as most of these workers leave the workforce when they are unable to continue working [5].

Work related injuries also impact on the turnover of companies and production levels, a study by estimated employer costs from the accidents, the study showed that this impacts on amongst other salary costs for replacement staff or overtime payments, production and productivity losses, retraining costs, personal injury claim compensation, repair bills, medical \& travel expenses and increased supervision. Government securities agencies around the world are established to manage and administer work related injuries and diseases though workers' compensation insurance.

Workers' compensation laws are beneficial to employers because they do not run the risk of being sued by their employees or a risk of a huge injury on duty claim that could potentially lead the company to bankruptcy. Workers' compensation insurance does not cover all the cost associated with work on duty claim but only fraction. Nearly all employers are required by laws applicable to relevant countries to have insurance product for such events. When employers register with such agencies, they also contribute an annual premium towards the Fund (workers' compensation insurance) that is formed to pay for injury on duty claim and diseases acquired in the working environment.

The benefits of contributing towards the Fund include: 
- Ensure that all employees enter the labour market as fit and healthy as possible Promote a safe working environment.

- Provide compensation to injured employees.

- Take responsibility for the payment of reasonable medical expenses should it result from an injury sustained and the claim has been accepted.

\section{COIDA- Compensation Occupational Injuries and Diseases}

The Compensation for Occupational Injuries and Diseases Act, No 130 of 1993 (COIDA) provides for compensation for disablement caused by occupational injuries or diseases sustained or contracted by employees in the course of their employment, or for death resulting from such injuries or diseases. Employers are required to submit a Return of Earnings (ROEs) on an annual basis, furthermore employers to make regular contributions to the Compensation Fund (CF) on behalf of their employees. The return of earnings data forms the basis of determining the contributions pricing of products in line with the liabilities of covered.

In terms of the Compensation for Occupational Injuries and Diseases (COID) legislation, The Compensation Fund (CF) is mandated to manage its premiums determination process as follows:

- Determine premiums for the individual employer, sub-class of employers in line with their liabilities and also in terms of its insurance policy.

- Manage its assessment process and determine the period of assessment in accordance with the requirements of COID, Short-Term, Long-Term and Financial Services Board requirements.
- Experience rate employers on the basis of the number of claims submitted for a given period of time.

Against this background, availability of accurate and complete data is critical in deriving benefits for injured employees. There are currently high levels of noncompliance amongst by employers, particularly with regards the submission of ROEs. Other challenges that persevere are employers who do submit ROEs but submit incorrect or incomplete returns, these employers tend to under underdeclare their ROEs. The impact thereof is on the process of determining the contributions pricing of products and determining liabilities. Other adverse effects is underdeclaration or not submitting returns is that injured employers do not get benefits due to them and this significantly impacts on their livelihood and their quality of life thereafter.

\section{References}

1. Hsiao-Yu Yang (2013) Awareness of labor insurance coverage for occupational injuries and diseases among employees at small and large enterprises. Tzu Chi Med J 25: 108.

2. Koehoorn M, Tamburic L, Xu F, Alamgir $H$, Demers PA, et al. (2015) Characteristics of work-related fatal and hospitalised injuries not captured in workers' compensation data. Occup Environ Med 72: 413-420.

3. Chen Y, Chen FC (2013) Is your work making you sick? Problems of our occupational health systems, Socio Publishing Co., Ltd, Taipei.

4. OSHA (Occupational Safety and Health Administration) 2015 Adding inequality to injury: The costs of failing to protect workers on the job. U.S. Department of Labour.

5. Hrymak V, Perezgonzalez J (2007) The Costs and Effects of Workplace Accidents: 20 Case Studies from Ireland. Health and Safety Authority Series. 